\title{
DELAYED SPLENIC RUPTURE: AN ANUSUAL CAUSE OF ACUTE SURGICAL ABDOMEN
}

\author{
Vladimír Špaček, Pavel Jandík, Karel Šmejkal \\ Charles University in Prague, Faculty of Medicine in Hradec Králové: Department of Surgery
}

Summary: Authors describe an anusual case of acute abdomen after the traffic injury. They remind correct diagnosis of delayed splenic rupture and compare it with other literature findings.

Key words: Delayed splenic rupture; Traffic injury

\section{Introduction}

To make the diagnosis of delayed rupture of the spleen is sometimes difficult because of the presumed triviality of the precipitating injury, an unpredictable time lag between the injury and development of symptoms, and the possibility of atypical signs and symptoms remote from the bleeding spleen.

We would like to present one case history to illustrate the diagnostic difficulties caused by delayed rupture of the spleen. A case report is presented involving the patient who suffered from a ruptured spleen 3 weeks following an accident.

\section{Case}

23years old patient suffered the traffic injury in small velocity on his motorcycle. He felt down on his back, without unconsciousness and even finished his journey home. He visited his doctor next day and fracture of the sixth thoracic vertebra was discovered. He didn't complain of abdominal pain, investigation of his abdomen was negative and he was later discharged home with special fixation of the thorax.

He lived normal life, didn't even come for check up few days later. After three weeks he visited some dancing party and there started acute abdominal pain with weakness and faintness. He was urgently admitted at internal department intensive care. In ultrasound and later computerized tomography investigation second grade splenic rupture with free blood in abdominal cavity was found, nondislocated fracture of left eleventh rib, fluidothorax and anaemia were present. Patient was urgently operated on and spleen resection was performed. Intraoperatively there was found posttrau- matic pseudocyst of the upper pole of the spleen as a consequence of perforated subcapsular haematoma. Convalescens passed normally and patient was discharged after 11 days in very good condition. Spleen was controlled scintigraphically one month later and very good function was proved. Half a year after the accident patient feels well, doing sports and, of course, drives his motorcycle again.

\section{Discussion}

Delayed spleen rupture is being frequently discussed in literature, most unusual cases always representing the source of lessons for wide surgical public, therefore this affection is quite well kept in minds of outpatient surgical and orthopedical specialists. Nevertheless, in multiply traumatized patients or those with coincidence injury, as it was described in our case, delayed rupture of the spleen is particularly insidious affection and often may become even fatal complication of therapeutic procedure.

Possibly the longest interval between the injury and rupture of the spleen is reported from Australia. Deva (3) described the case with the five and half years' pause, nearly resulting in patient's death. Fernandes (4) describes two and half years' interval. Bioli (2) introduces collection of 18 patients with delayed rupture of the spleen with the average interval of six and half days.

Specifity of diagnosis grows today due to the computerized tomography $(\mathrm{CT})$. Investigation, which frequently represents the basic attribute in decision for conservative therapy. Kluger (6) evaluates CT findings of the splenic lesions in relation to nonoperative management or surgery. He considers this investigation to be the „evolution in injury“. Thus there can be found even those spleen traumas un- 
detected on initial abdominal CT scans. On collection of 421 patients with rupture of the spleen Wilkinson (13) in the year 1989 warns against a high number of false negative CT diagnoses in cases of delayed splenic ruptures. This is very important decision to be made before discharge, of course, mainly in cases of sportsmen and contact sportsmen. Knudson (7) even recommends these groups to be candidates for radiologic procedures, such as angioembolization. Lynch (8) in the set of 58 child splenic injuries treated conservatively assessed the global time of observation (radiographical healing). Mean time in the grade $\mathrm{I}$ is 3,1, grade II 8,2 , grade III 12,1 , and grade IV laceration is 20,7 weeks, respectively. In the cases when spleen mass preservation and prevention of splenectomy was performed intraoperatively, using different surgical techniques and synthetic materials to stop bleeding, there exists large possibility of late spleen complications such as subdiaphragmatic collection or delayed spleen rupture. Dispensarization of these patients must be thus adapted.

Similar decission must be taken in cases of transport timing. Time necessary for diagnostic procedures and transport limit diagnostical and therapeutical possibilities and cause a risk of inadequate therapy in case of a sudden debasement of the patients' condition (1).

Our case belongs in this group of „nondetected“ spleen ruptures, because during primary investigation no spleen lesion was discovered and it clinicaly manifested only after 3 weeks. From the same group we found in literature similar cases, when delayed rupture of the spleen manifestated as a scrotal hematoma (11), or ruptured spleen imitated acute appendicitis (10). Gores (5) reported a case of delayed spleen bleeding after colonoscopy. Intraoperatively it was found disrupted splenocolic ligament with decapsulation of distal pole of the spleen.

Another range of splenic ruptures are in patologically changed ones. They mean for instance hypersplenic syndroms, mainly hemoblastoses. Taylor (12) describes spleen ruptures in patients with rheumatoid arthritis or rare spleen bleeding subsequent streptokinase administration due to myocardial infarction half a year after the blunt abdominal injury (9).

\section{Conclusion}

We conclude that „delayed rupture“ of the spleen is a true clinical entity and it represents life threatening risk not only in blunt abdominal injuries. It may represent the source of unpleasant surprisings even today, in era of wide diagnostic and therapeutic possibilities. Evaluation of individual cases always opens the basic question: is it a delayed rupture of the spleen or uncovered primary injury?

\section{Literature}

1. Ambacher T, Reisener KP, Kasperk R, Schumpelick V. Transport management in blunt abdominal trauma.Case report of a patient with delayed diagnosis of splenic rupture.Zentralbl, Chir 1999;124(11):1036-40.

2. Bioli F, Gattoni F, Tagliaferri B et al. Blunt trauma of the spleen: the delayed rupture in computed tomography. Bildgebung $1994 \mathrm{Sep} ; 61(3): 210-5$.

3. Deva AK,Thompson JF. Delayed rupture of the spleen $51 / 2$ years after conservative managenent of traumatic splenic injury. Aust N Z J Surg 1996 Jul;66(7):494-5

4. Gores PF, Simso LA. Splenic injury during colonoscopy. Arch Surg 1989Nov; 124(11):1342.

5. Fernandes CM. Splenic rupture manifesting two years after diagnosis of injury. Acad Emerg Med 1996Oct;3(10):946-7.

6. Kluger Y, Paul DB, Raves JJ et al. Delayed rupture of the spleen - myths,facts and their importance: case reports and literature rewiew. J Trauma 1994 Apr;36(4):568-71.

7. Knudson MM, Maull KI. Nonoperative manegement of solid organ injuries. Past, present and future. Surg Clin North Am 1999Dec;79(6):1357-71.

8. Lynch JM, Meza MP, Newman B et al. Computed tomography grade of splenic injury is predictive of the time required for radiographic healing. J Pediatr Surg 1997Jul;32(7):1093-5.

9. Nam R, Carr MM, Jamieson CG. Delayed rupture of the spleen and streptokinase therapy. Can J Surg 1996Apr;39(2):151-4.

10. Sriskandavarman S. Delayed rupture of the spleen can masquerade as appendicitis. Ann R Coll Surg Engl 1984 Jul;66(4):300.

11. Sujka SK, Evans EJ, Nigam A. Delayed rupture of the spleen presenting as a sc rotal hematoma. J Trauma 1986 Jan;26(1):85-6.

12. Taylor JL, Middleton MD. Delayed rupture of the spleen in theumatoid arthritis Ann Rheum Dis 1990 Jul;49(7):545-6.

13. Wilkinson AE. Rupture of the spleen.An analysis of 421 cases. S Afr J Surg 1989 Jun;27(2):74-5.

Submited February 2002.

Accepted April 2002.

MUDr. Vladimír Špaček, Mánesova 902, 50002 Hradec Králové, Czech Republic. e-mail: spacekv@post.cz 